\title{
Primary aldosteronism as an endocrinological challenge - old doubts and new diagnostic possibilities
}

\author{
Ewa Cyrańska-Chyrek', Małgorzata Grzymisławska², Marek Ruchała \\ ${ }^{1}$ Department of Endocrinology, Metabolism and Internal Medicine, Poznan University of Medical Sciences, Poland \\ ${ }^{2}$ Department of Anatomy, Poznan University of Medical Sciences, Poland
}

\begin{abstract}
Hypertension constitutes a common clinical problem worldwide. In fact, a systematic increase in its detection is predicted in the following years, with early detection, accurate diagnosis and effective treatment of hypertension being a priority. The most common endocrinological cause of hypertension is primary aldosteronism. What is more, elevated aldosterone levels cause a deterioration in blood pressure normalization, diabetes, and significantly increase cardiovascular risk. There are two distinct causes of primary aldosteronism - aldosterone producing adenoma (APA), as well as bilateral adrenal hyperplasia (BAH) and proper differentiation between APA and BAH has clinical implications. In the case of the former adrenalectomy is advised, whereas the latter is followed by introduction of proper pharmacotherapy with aldosterone antagonists (spironolactone, eplerenone).
\end{abstract}

Keywords: primary aldosteronism, adrenal tumor, aldosterone producing adenoma, bilateral adrenal hyperplasia, adrenal $\mathrm{CT}$, adrenal venous sampling.

\section{Introduction - epidemiology of hypertension}

Hypertension is a common, serious clinical problem which currently affects about 1 billion patients worldwide. Global prognoses indicate further systematic increase in the affected population exceeding 1.56 billion in 2025 [1]. Furthermore, hypertension constitutes a challenge for health care all over the world and its early detection and effective treatment are a priority.

The majority of cases, about 90-95\%, are described as primary hypertension, therefore it is not possible to precisely determine its etiology. Hence, the unfortunate name of idiopathic hypertension. On the other hand, over 40 causes of secondary hypertension have been identified up to date, including ones with an endocrinological background, the most common being hypertension with primary aldosteronism, but also oth- ers such as hyper- and hypothyroidism, hypercortisolemia, hyperparathyroidism or pheochromocytoma [3].

Taking into consideration the fact that $20-30 \%$ of patients are diagnosed with resistant hypertension, it seems obvious and necessary to seek for the underlying cause. This in turn provides a chance for an individualized patient approach and allows for effective treatment [4].

\section{Clinical manifestations and etiopatho- genesis of primary aldosteronism}

Primary aldosteronism (PA) is now considered to be the most common and potentially reversible secondary cause of hypertension which causes about 5 $13 \%$ cases of hypertension [5-7]. It is estimated that an excess of aldosterone occurs in 5 to $40 \%$ cases of 
hypertension [8-10]. According to some authors, this phenomenon can no longer be called an epidemic [11-13] and, on the contrary Galati SJ et al. suggest that many patients still remain undiagnosed [14].

In the literature, primary aldosteronism (PA) is also referred to as Conn syndrome [15]. It is clinically manifested by fatigue and periodic skeletal muscles weakness, hipokaliemia and metabolic alkalosis. The description of the syndrome from 1955, is frequently considered to be the first published one, although 2 years prior to its publication, two cases of PA hypertension were presented by a Polish practitioner Michał Lityński [16].

Until recently, the coincidence of adrenal tumor with resistant hypertension and spontaneous hypokalemia were treated as clear indication of primary aldosteronism. However, in the past 60 years since PA was first described, a number of discoveries have been made which frequently contradict the original assumptions related to the condition.

\section{Diagnostic difficulties in primary aldosteronism differentiation}

It is currently believed that the most common causes of PA are bilateral adrenal hyperplasia (BAH), which constitutes about $60 \%$ of cases, and aldosterone producing adenoma (APA), aka. aldosteronoma, which adds up to $40 \%$. What is interesting, until recently the ratio had been believed to be quite the opposite, with APA causing two-thirds of PA cases [17]. However, scientific advancement has facilitated a breakthrough in determining PA etiopathogenesis.

Interestingly, with the increased availability of imaging techniques (especially computed tomography, $\mathrm{CT}$ ) numerous doubts have arisen concerning the differentiation between the causes of PA. They point to the fact that adrenal adenoma imaging in a patient with hypertension and hypokalemia is not decisive in aldosteronoma diagnosis. In fact, there is a possibility of imaging a non-functioning adenoma (NFA) instead of a real underlying cause, i.e. a contralaterally located microadenoma, which was not revealed in the CT [18].

Young WF et al. analyzed 203 PA patients. They showed that proper differentiation between APA and BAH was performed only in $53 \%$ of cases. As a result of biochemical and imaging analysis, $20 \%$ of patients would be incorrectly disqualified from adrenalectomy, whereas in another $25 \%$ the surgery type would be improper. Diagnostic difficulties are further enhanced by the fact that aldosteronomas are frequently microadenomas (with a diameter $<1 \mathrm{~cm}$ ); thus, failure to present them in the CT with concomitant clinical hyperaldosteronism manifestations may incorrectly imply hyperaldosteronism [19].

Reliable diagnosis associated with definite lateralization of hormonally active lesions has been possible since 1967, when adrenal venous sampling (AVS) was introduced. Unfortunately, it is a difficult and invasive method, especially due to the anatomical limitations (mainly small size of the right suprarenal vein) and the catheterization of both veins in order to compare the results. Moreover, it is available only in very few medical centers. The Mayo Clinic experience shows that AVS procedures allow for an accurate diagnosis in $95.5 \%$ of cases, whereas diagnosis based exclusively on the biochemical and imaging tumor assessment is correct only in $58.6 \%$ of patients [20].

The authors point out that suprisingly only $25 \%$ of the Mayo Clinic patients consents to AVS; the remaining $75 \%$ choose pharmacotherapy. Artl W. et al. additionally stress that even in the most advanced centers, the percentage of successful AVS procedures is not higher than $40-70 \%$, mainly because of anatomical limitations in the course of procedure [21].

\section{Variety of clinical manifestations in primary aldosteronism}

Research conducted in recent years has shown that PA is also present in normotensive patients [22-25], as well as those with mild to moderate hypertension without concomitant hypokalemia. The Italian researchers' study on a large number of 1125 patients indicate that a large percentage of patients shows PA independent of normokalemia. In fact, hypokalemia was diagnosed in $48 \%$ of APA patients and $16.9 \%$ of idiopathic hyperaldosteronism patients (IHA).

Furthermore, aldosteronoma is diagnosed more frequently in centers where AVS is available. In such cases the APA to IHA ratio is $62.5 \%$ to $37.5 \%$ respectively. On the other hand, in the centers where AVS is not accessible the APA to IHA ratio is 35\% to $65 \%$ respectively [27].

Numerous researchers stress the incidence of primary aldosteronism in hypertensive patients without concomitant hypokalemia. According to some authors, it points to the necessity of widening PA screening to both normokalemic and normotensive patients [28-30]. On the other hand, Kaplan NM points out 
that the moderate hypertension (with RR values of $160-180 \mathrm{mmHg} / 100-110 \mathrm{mmHg}$ ) includes up to $25 \%$ of hypertensive patients, whereas an adrenal incidentaloma is misdiagnosed for aldosteronoma in only $1 \%$ of cases of adrenal incidentaloma [31, 32].

Adrenal incidentalomas (AI) have become another fundamental issue. According to the literature, PA is diagnosed in adrenal incidentaloma patients in 1.6-3\% of cases [33, 34]. However, due to many limitations and difficulty in maintaining conditions necessary for proper diagnosis of aldosteronemia, as well as doubts concerning proper cut-off point in the aldosterone to renin ratio (ARR), the influence of various drug groups and clinical states on the ARR interpretation must be taken into account [35]. Moreover, in women both aldosterone and ARO levels strictly correlate with the phase of the menstrual cycle which induces elevated aldosterone level (> $15 \mathrm{ng} / \mathrm{ml}$ ), as well as PA overdiagnosis. It is the case in $30 \%$ of female patients in the $7^{\text {th }}$ day of cycle, and it increases even to $70 \%$ in the $21^{\text {st }}$ day $[36,37]$. Ahmed $\mathrm{AH}$ et al. suggest the need of establishing separate norms and cut-off points not only for men and women, but also for individual menstrual cycle phases [38].

\section{Hyperaldosteronism's clinical implications}

The diagnosis and effective treatment of PA is even more important in terms of increased occurrence of cardiovascular incidents, strokes and arrhythmias in PA patients. As it turns out, PA patients are more at risk of a myocardial infarct than those suffering from essential hypertension $(\mathrm{EH})$, with the $\mathrm{PA}$ to $\mathrm{EH}$ ratio of $20 \%$ to $8 \%$ respectively. They are also more prone to sustain a stroke or transient ischemic attack (11\% PA vs. $3 \%$ $\mathrm{EH})$, to have arrhythmias (15\% PA vs. 3\% EH), as well as to suffer from chronic lower limb ischemia (65\% PA vs. $2 \% \mathrm{EH}$ ) [39].

Numerous analyses indicate a more common incidence of pre-diabetic states and type 2 diabetes in PA patients than in cases of obese and/or with essential hypertension patients [40, 41, 42]. Modern medical knowledge clearly states that undiagnosed or ineffectually treated PA definitely deteriorates maintaining sugar levels and increases albuminuria which constitutes an independent cardiovascular risk factor [43, 44]. Many clinical research points out to adverse metabolic profile observed in PA patients. In fact, they have shown a lower adiponectin concentration, higher resistin and leptin levels, as well as increased insulin resistance [42, 45-47]. Additionally, in comparison to essential hypertension patients, PA patients run the risk of accelerated development of cardiac remodeling, i.e. thickening and increased mass of the left ventricle muscle $[48,49]$. The above mentioned conclusions may partially account for an increased cardiometabolic risk in comparison with essential hypertension (ES), as well as higher mortality rates observed in these patients [50].

Aldosterone activates mineralocorticoid receptors (MR) found in the heart, blood vessels and the brain. Additionally, the biological effect of their stimulation are heart and blood vessels fibrosis, pro-arrhythmogenic and pro-inflammatory action, as well as vascular endothelium damage which, as a consequence, increases the risk of cardiovascular system disorders [51].

\section{Vast variety of aldosterone mechanisms}

In recent years, the dependence between elevated aldosterone level and hemostatic disorders leading to the increased risk of thromboembolic incidents has been shown. It was observed that aldosterone impairs vascular endothelium function and fibrinolysis, as well as increases oxidative stress. Furthermore, in the experimental arterial thrombosis rat-models it has been proven that long-term aldosterone administration increases the thrombotic process [52]. Pro-thrombotic aldosterone action is complex and depends on the activation of the primary hemostasis, pro-coagulation and antifibrinolytic activity, as well as a decrease in nitric oxide bioavailability and an increase in oxidative stress. What is more, hormone effects were not fully removed after mineralocorticoid receptor blockade thus implying the role of alternative mechanisms in the hormone pro-coagulation activity [53].

It was claimed that aldosterone, similarly to other steroid hormones, acts only through specific cytoplasmic mineralocorticoid receptor MR. In view of recent data, the theory regarding non-genomic (local) aldosterone action has become more relevant. The aforementioned action has been confirmed in many experimental models in various cell types, such as vascular smooth muscle cells, lymphocytes, and endothelial cells [54. 55]. Furthermore, aldosterone has become more important than expected in the cardiovascular system pathology, as a local messenger. Addition- 
ally, the majority of experimental data indicate that non-genomic (local) aldosterone activity is visible within a few minutes and is not blocked by traditional MR receptor antagonists (spironolactone, canrenone and eplerenone) $[56,57,58]$. Therefore, the role of new membrane receptors is alleged, as well as alternative routes associated with the activity of potassium ions, angiotensin II or the activation of glucocorticoid receptor [59].

Due to the MR receptor presence in the adipose tissue and the vascular endothelium, earlier administration of mineralocorticoid receptor antagonists is advisable in PA patients $[60,61,62]$. Since primary aldosteronism has multifold and serious consequences, some authors included the MR receptor antagonists as a first line treatment [63[, even in patients with mild and moderate hypertension [64].

In addition, comparative studies are carried out aimed to verify which of the MR receptor antagonists (spironolactone or eplerenone) is more effective. Some authors suggest a better hypotensive effect of spironolactone in PA patients [65], others did not observe any difference in the hypotensive effect [66].

\section{"Lost subtype" of primary hyperaldos- teronism}

Research conducted by Spath M and Willenberg HS shows that although some adrenal adenomas are classified as aldosteronoma, they actually also overproduce cortisol. Thus, the comorbidity of hyperaldosteronism and subclinical hypercortisolemia is referred to as primary aldosteronism/subclinical Cushing syndrome (PA/ $\mathrm{SCS})$. As a consequence, it may make the PA diagnosis difficult, and at the same time cause cortisol deficiency following adrenalectomy. The authors indicate that aldosterone- and cortisol-co-secreting tumor should be suspected in case of any patient with a tumor $>2.5 \mathrm{~cm}$, partial suppression in dexamethasone suppression test and or increased corticosteroid excretion in urine. The authors refer to such combination of symptoms as the "lost subtype of primary aldosteronism" [67, 69].

The aforementioned problem may affect even 10\% of PA patients which indicates SCS screening in every PA case [69]. These observations are confirmed by Hiraishi $\mathrm{K}$ et al. They carried out an analysis of 38 patients with PA - in 21\% (8/38 patients) they recognized the coexistence of PA / SCS. These patients were older, adrenal tumors were of larger size, presented higher levels of kalemia and lower levels of serum aldosterone. More- over, six of them require replacement after corticosteroid therapy adrenalectomy [70, 71].

On the other hand, some contradictory opinions have also appeared. In fact, Markou A et al. concluded that elevated aldosterone serum levels may also be observed in hypertensive patients without PA, and they result from glomerular zone increased response to the ACTH excessive stimulation. These patients also benefit from the MR antagonist treatment [72].

\section{Imaging limitations in aldosteronoma}

In case of difficult AVS availability, doubtful imaging diagnosis as well as bilateral lesions and/or lack of patient's consent for invasive treatment, scintigraphy with iodomethyl-norcholesterol (NP-59) may be considered aimed at hormonally active lesion lateralization [73]. The analysis of the research conducted between 1979-2003, where the total of 686 patients were included, presented NP-59 scintigraphy sensitivity at the level of $86 \%$, specificity $-78 \%$, and accuracy $-82 \%$ [74]. As a result, this method was considered valuable in the surgery qualification [75].

Nevertheless, its limitations should also be considered. Due to the examination's low resolution and the overlapping activity of the liver and/or the intestines, it is not useful in terms of microadenomas and adenomas with the diameter $<1.5 \mathrm{~cm}$. At the same time, it requires special preparation of the patient in order to obtain optimal uptake of radiotracer which includes discontinuation of the angiotensin II receptor blocker (ARB), angiotensin-converting-enzyme inhibitors (ACE-I), as well as diuretics in 4-6 weeks prior to the examination according to a given protocol [76].

\section{New updates}

New information concerning a newly discovered rare PA form has recently surfaced in the literature, described as a surgically treatable unilateral adrenal hyperplasia (UAH). Goh BK et al. analyzed 30 described patients suffering from UAH, hypertension, hypokalemia and elements of primary aldosteronism who were successfully treated by means of unilateral adrenalectomy [77].

Moreover, new data have been emerging regarding the association between PA and level of parathormone concentration (PTH). In fact, this phenomenon resembles a vicious circle, i.e. aldosterone increases the parathyroid hormone secretion by binding with mineralocorticoid receptors (MR) found in the parathyroid cells, 
whereas PTH directly stimulates aldosterone synthesis in the adrenal cells glomerular zone. PTH increases the risk of cardiovascular damage by binding with PTH receptor (PTHR) present in cardiomyocytes and vascular smooth muscle cells. Additionally, by its pro-inflammatory activity PTH may increase the cardiovascular damage. MR antagonist therapy combined with angiotensin-converting-enzyme inhibitors (ACE-I) suppress the mutual dependence $[78,79]$.

Zhang LX et al. observed that the measurement of PTH may be vital for aldosteronoma diagnosis. 142 patients with adrenal tumor were qualified for the research and in 84 cases APA was diagnosed, whereas in 58 patients a non-functioning adenoma (NFA) was found. Furthermore, PTH level was significantly increased, while the level of calcium and phosphates was considerably decreased in APA patients as compared to NFA cases. In addition, the tilt test revealed that a change in PTH concentration ( $\triangle \mathrm{PTH}$ ) was greater in APA patients than in NFA patients. The author presents an additional auxiliary tool in APA diagnosis, i.e. measuring both PTH at the baseline level and in the tilt test in cases where primary aldosteronism is suspected [80].

Due to a still growing number of NT patients, as well as constant development in data regarding secondary hypertension, including PA, PA itself should be considered each time a hypertensive patient is treated. The correct diagnosis of the underlying cause of hypertension allows for effective treatment or at least improvement. As a consequence, it enhances patient cooperation and results in better long-term treatment effects.

Limitations of the biochemical and imaging examinations in the PA diagnosis may result in the decrease in the incidence of misdiagnoses, both false-positive, and false-negative. Despite a number of doubts, it is necessary and beneficial to make attempts at accurate diagnoses, as well as to initiate adequate treatment. What is more, owing to the analyzes conducted on 5 continents, it is known that the majority of treated patients are cured or achieve clinical improvement, respectively: $55 \%$ to $45 \%$ (Brisbane), $70 \%$ to $30 \%$ (Santiago), $65 \%$ to 35\% (Torino), 33\% to $66 \%$ (Rochester), 40\% to 55\% (Singapore) [10]. The aforementioned observations indicate an urgent and inevitable need to optimize the biochemical diagnosis (aldosterone, ARO, PRA), as well as PA imaging. Moreover, due to the visible limitations of the latter, also a wider access to adrenal venous sampling procedure is necessary.

\section{Summary}

40 causes of secondary hypertension have been recognized up to date, where primary aldosteronism constitutes the most common reversible cause, present in $5-13 \%$ of hypertensive patients.

The most common causes of PA are bilateral adrenal hyperplasia ( $60 \%$ of cases), and aldosterone producing adenoma aka. aldosteronoma (40\%). However, imaging an adrenal adenoma during imaging examination in a hypertensive and hypokalemic patient does not correspond to diagnosing aldosteronoma. In fact, it is difficult to make a correct diagnosis due to the increasing number of incidentalomas (the possibility of imaging a non-functioning adenoma), as well as to the possibility of normokalemia and normotension in PA patients. Correct qualification of PA adenoma patients to adrenalectomy eliminates and/ or markedly limits the adverse reactions to increased aldosterone level. Reliable functioning lesion lateralization has been possible since 1967 when adrenal venous sampling was introduced. Nevertheless, due to anatomical limitations and technical difficulties it is available only in very few medical centers.

In addition, the concomitance of increased aldosterone level and hemostatic disorders was described, including vascular endothelium damage, fibrinolysis impairment and increased oxidative stress. As a consequence, it influences the increased occurrence of cardiovascular incidents, cerebral strokes and arrhythmia in PA patients when compared to patients suffering from essential hypertension.

Due to a multifold serious consequences of hyperaldosteronism, sooner administration of mineralocorticoid receptor antagonists in the treatment of PA patients was recommended, even in cases of mild and moderate hypertension. Recent research has pointed to a possible comorbidity of hyperaldosteronism with subclinical hypercortisolemia ("the lost subtype of primary aldosteronism"). It is also referred to as primary aldosteronism/subclinical Cushing syndrome (PA/SCS) which makes the diagnosis difficult, and may be the cause of cortisol deficiency following adrenalectomy.

Numerous attempts at the differentiation of non-functioning adenomas and aldosteronomas are made. The association between PA and increased levels of parathyroid hormone (PTH) was observed. In fact, it resembles a vicious cycle which contributes to earlier damage of the cardiovascular system by means of binding with PTH receptor (PTHR), present in cardiomyocytes and vascular smooth muscle cells. Thera- 
py based on MR antagonists and angiotensin-converting-enzyme inhibitors results in the suppression of the mutual dependence.

The limitations of biochemical and imaging examinations imply the necessity of better access to adrenal venous sampling procedure. Proper qualification of aldosteronoma patients following adrenalectomy results in higher percentage of cured patients or achieving clinical improvement.

\section{Acknowledgements}

\section{Conflict of interest statement}

The authors declare no conflict of interest.

\section{Funding sources}

There are no sources of funding to declare.

\section{References}

1. Kearney PM, Whelton M, Reynolds K, Muntner P, Whelton PK, He J. Global burden of hypertension: analysis of worldwide data, Lancet. 2005 Jan 15-21;365(9455):21723.

2. Beevers G, Lip GYH. O'Brien E. The pathophysiology of hypertension. BMJ 2001;322: 912--916

3. Makris A, Seferou M, Papadopoulos DP. Resistant hypertension workup and approach to treatment, Int J Hypertens. 2010 Dec 26;2011:598694.

4. Calhoun DA, Jones D, Textor S, Goff DC, Murphy TP, Toto RD, White A, Cushman WC, White W, Sica D, Ferdinand K, Giles TD, Falkner B, Carey RM. American Heart Association Professional Education Committee.

5. Resistant hypertension: diagnosis, evaluation, and treatment: a scientific statement from the American Heart Association Professional Education Committee of the Council for High Blood Pressure Research, Circulation. 2008 Jun 24;117(25):e510-26.

6. Young WF Jr. Primary aldosteronism: A common and curable form of hypertension. Cardiol Rev. 1999 Jul-Aug;7(4):207-14

7. Schwartz GL, Screening for adrenal-endocrine hypertension: overview of accuracy and cost-effectiveness, Endocrinol Metab Clin North Am. 2011 Jun;40(2):27994, VII.

8. Faselis C, Doumas M, Papademetriou V. Common secondary causes of resistant hypertension and rational for treatment. Int J Hypertens. 2011 Mar 2;2011:236239.

9. Sarwar MS, Islam MS, Al Baker SM, Hasnat A, Resistant hypertension: underlying causes and treatment, Drug Res (Stuttg). 2013 May;63(5):217-23.

10. Rossi GP. Prevalence and diagnosis of primary aldosteronism, Curr Hypertens Rep. 2010 Oct;12(5):342-8.

11. Mulatero P, Stowasser M, Loh KC, Fardella CE, Gordon RD, Mosso L, Gomez-Sanchez CE, Veglio F, Young WF Jr. Increased diagnosis of primary aldosteronism, including surgically correctable forms, in centers from five continents, J Clin Endocrinol Metab. 2004 Mar;89(3):1045-50.

12. Kaplan NM, Is there an unrecognized epidemic of primary aldosteronism? Hypertension. 2007 Sep;50(3):454-8; discussion 454-8.
13. Stiefel P, Aparicio R, Carneado J, Pamies E, Villar J. The current epidemic of primary aldosteronism: causes and consequences, J Hypertens. 2004 Oct;22(10):2040-2.

14. Krishnan PH, MacDonald T. The current epidemic of primary aldosteronism: causes and consequences. J Hypertens. 2004 Oct;22(10):2039-40

15. Galati SJ, Hopkins SM, Cheesman KC, Zhuk RA, Levine AC. Primary aldosteronism: emerging trends, Trends Endocrinol Metab. 2013 Sep;24(9):421-30.

16. Conn JW. Primary aldosteronism: a new clinical syndrome. J Lab Clin Med. 1955;43: 3-17

17. Lityński M. Nadciśnienie tętnicze wywołane guzami korowo-nadnerczowymi, Pol Tyg Lek. 1953;8: 204-208

18. Young WF Jr. Minireview: primary aldosteronism--changing concepts in diagnosis and treatment, Endocrinology. 2003 Jun;144(6):2208-13

19. Takase $\mathrm{K}$ et al, Adrenal venous sampling revisited - Crucial role in the management of primary aldosteronism Patients, ECR 2012

20. Young WF, Stanson AW, Thompson GB, Grant CS, Farley $D R$, van Heerden JA, Role for adrenal venous sampling in primary aldosteronism, Surgery. 2004 Dec;136(6):122735.

21. Lim V, Guo Q, Grant CS, Thompson GB, Richards ML, Farley DR, Young WF Jr, Accuracy of adrenal imaging and adrenal venous sampling in predicting surgical cure of primary aldosteronism, J Clin Endocrinol Metab. 2014 Aug;99(8):2712-9.

22. Arlt W.: A detour guide to the Endocrine Society Clinical Practice Guideline on case detection, diagnosis and treatment of patients with primary aldosteronism, Eur J Endocrinol. 2010;162:435-438

23. Shiroto $H$, Ando H, Ebitani I, Hara M, Numazawa K, Kawamura S, Sasaki H. Normotensive primary aldosteronism, Am J Med. 1980 Oct;69(4):603-6.

24. Kono $\mathrm{T}$, Ikeda F, Oseko F, Imura H, Tanimura H. Normotensive primary aldosteronism: report of a case, J Clin Endocrinol Metab. 1981 May;52(5):1009-13.

25. Vantyghem MC, Ronci N, Provost F, Ghulam A, Lefebvre J, Jeunemaitre X, Tabarin A. Aldosterone-producing adenoma without hypertension: a report of two cases, Eur J Endocrinol. 1999 Sep;141(3):279-85.

26. Médeau V, Moreau F, Trinquart L, Clemessy M, Wémeau $J \mathrm{~L}$, Vantyghem MC, Plouin PF, Reznik Y. Clinical and biochemical characteristics of normotensive patients with primary aldosteronism: a comparison with hypertensive cases, Clin Endocrinol (Oxf). 2008 Jul;69(1):20-8.

27. Williams JS, Williams GH, Raji A, Jeunemaitre X, Brown NJ, Hopkins PN, Conlin PR. Prevalence of primary hyperaldosteronism in mild to moderate hypertension without hypokalaemia. J Hum Hypertens. 2006 Feb;20(2):12936.

28. Rossi GP, Bernini G, Caliumi C, Desideri G, Fabris B, Ferri C, Ganzaroli C, Giacchetti G, Letizia C, Maccario M, Mallamaci F, Mannelli M, Mattarello MJ, Moretti A, Palumbo G, Parenti G, Porteri E, Semplicini A, Rizzoni D, Rossi E, Boscaro M, Pessina AC, Mantero F; PAPY Study Investigators. A prospective study of the prevalence of primary aldosteronism in 1,125 hypertensive patients. J Am Coll Cardiol. 2006 Dec 5;48(11):2293-300.

29. Mulatero P, Stowasser M, Loh KC, Fardella CE, Gordon $R D$, Mosso $L$ et al. Increased diagnosis of primary aldo- 
steronism, including surgically correctable forms, in centers from five continents. J Clin Endocrinol Metab. 2004;89: 1045-1050.

30. Gordon RD, Stowasser M, Primary aldosteronism: the case for screening, Nat Clin Pract Nephrol. 2007 Nov;3(11):582-3.

31. Ganguly A. Prevalence of primary aldosteronism in unselected hypertensive populations: screening and definitive diagnosis. J Clin Endocrinol Metab. 2001;86: 40024004.

32. Kaplan NM. Primary aldosteronism: A contrarian view, Rev Endocr Metab Disord. 2011 Mar;12(1):49-52

33. Kaplan NM, Primary aldosteronism: evidence against a second epidemic, J Hypertens. 2012 Oct;30(10):1899902.

34. Mantero F, Terzolo M, Arnaldi G, Osella G, Masini AM, Alì A, Giovagnetti $M$, Opocher $G$, Angeli A. A survey on adrenal incidentaloma in Italy. Study Group on Adrenal Tumors of the Italian Society of Endocrinology, J Clin Endocrinol Metab. 2000 Feb;85(2):637-44

35. Barzon L, Scaroni C, Sonino N, Fallo F, Gregianin M, Macrì C, Boscaro M. Incidentally discovered adrenal tumors: endocrine and scintigraphic correlates, J Clin Endocrinol Metab. 1998 Jan;83(1):55-62

36. Funder J, Carey R, Fardella C, Gomez-Sanchez C, Mantero F, Stowasser M, Young W, Montori VM, Case detection, diagnosis, and treatment of patients with primary aldosteronism: an Endocrine Society clinical practice guideline, Eur J Endocrinol. 2009 Sep 30.

37. Fommei E, Ghione S, Ripoli A, Maffei S, Di Cecco P, lervasi $A$, Turchi $S$. The ovarian cycle as a factor of variability in the laboratory screening for primary aldosteronism in women, J Hum Hypertens. 2009 Feb;23(2):130-5.

38. Pizzolo F, Raffaelli R, Memmo A, Chiecchi L, Pavan C, Guarini P, Guidi GC, Franchi M, Corrocher R, Olivieri O. Effects of female sex hormones and contraceptive pill on the diagnostic work-up for primary aldosteronism, J Hypertens. 2010 Jan;28(1):135-42.

39. Ahmed AH, Gordon RD et al, Are women more at risk of false-positive primary aldosteronism screening and unnecessary suppression testing than men?, J Clin Endocrinol Metab. 2011 Feb;96(2):E340-6.

40. Weiner ID. Endocrine and hypertensive disorders of potassium regulation: primary aldosteronism, Semin Nephrol. 2013 May;33(3):265-76.

41. Reincke $M$, Meisinger $C$, Holle R, Quinkler $M$, Hahner $S$, Beuschlein F, Bidlingmaier M, Seissler J, Endres S; Participants of the German Conn's Registry. Is primary aldosteronism associated with diabetes mellitus? Results of the German Conn's Registry, Horm Metab Res. 2010 Jun;42(6):435-9

42. Hanslik G, Wallaschofski $H$, Dietz A, Riester A, Reincke M, Allolio B, Lang K, Quack I, Rump LC, Willenberg HS, Beuschlein F, Quinkler M, Hannemann A; participants of the German Conn's Registry. Increased prevalence of diabetes mellitus and the metabolic syndrome in patients with primary aldosteronism of the German Conn's Registry, Eur J Endocrinol. 2015 Nov;173(5):665-75.

43. Chen W, Li F, He C, Zhu Y, Tan W. Elevated prevalence of abnormal glucose metabolism in patients with primary aldosteronism: a meta-analysis, Ir J Med Sci. 2014 Jun;183(2):283-91.
44. Sechi LA, Di Fabio A, Bazzocchi M, Uzzau A, Catena C. Intrarenal hemodynamics in primary aldosteronism before and after treatment, J Clin Endocrinol Metab. 2009 Apr;94(4):1191-7.

45. Rossi GP, Bernini G, Desideri G, Fabris B, Ferri C, Giacchetti G, Letizia C, Maccario M, Mannelli M, Matterello MJ, Montemurro D, Palumbo G, Rizzoni D, Rossi E, Pessina AC, Mantero F; PAPY Study Participants, Renal damage in primary aldosteronism: results of the PAPY Study, Hypertension. 2006 Aug;48(2):232-8.

46. Fallo F, Della Mea P, Sonino N, Bertello C, Ermani M, Vettor R, Veglio F, Mulatero P. Adiponectin and insulin sensitivity in primary aldosteronism, Am J Hypertens. 2007 Aug;20(8):855-61.

47. Mosso LM, Carvajal CA, Maiz A, Ortiz EH, Castillo CR, Artigas RA, Fardella CE. A possible association between primary aldosteronism and a lower beta-cell function, J Hypertens. 2007 Oct;25(10):2125-30.

48. Fischer $E$, Adolf $C$, Pallauf A, Then C, Bidlingmaier $M$, Beuschlein F, Seissler J, Reincke M. Aldosterone excess impairs first phase insulin secretion in primary aldosteronism, J Clin Endocrinol Metab. 2013 Jun;98(6):2513-20.

49. Muiesan ML, Salvetti M, Paini A, Agabiti-Rosei C, Monteduro C, Galbassini G, Belotti E, Aggiusti C, Rizzoni D, Castellano M, Agabiti-Rosei E. Inappropriate left ventricular mass in patients with primary aldosteronism, Hypertension. 2008 Sep;52(3):529-34.

50. Iacobellis G, Petramala L, Cotesta D, Pergolini M, Zinnamosca L, Cianci R, De Toma G, Sciomer S, Letizia C. Adipokines and cardiometabolic profile in primary hyperaldosteronism, J Clin Endocrinol Metab. 2010 May;95(5):2391-8.

51. Karagiannis A, Treatment of primary aldosteronism: Where are we now?, Rev Endocr Metab Disord. 2011 Mar;12(1):15-20.

52. Kotlyar E, Vita JA, Winter MR, Awtry EH, Siwik DA, Keaney JF Jr, Sawyer DB, Cupples LA, Colucci WS, Sam F. The relationship between aldosterone, oxidative stress, and inflammation in chronic, stable human heart failure, J Card Fail. 2006 Mar;12(2):122-7.

53. Silvestre J.S. Robert V. Heymes C. Aupetit-Faisant B. Mouas C. Moalic J.M. Swynghedauw B. Delcayre C. Myocardial production of aldosterone and corticosterone in the rat. Physiological regulation. J. Biol. Chem. 1998;273: 4883-4891

54. Takeda Y. Yoneda T. Demura M. Miyamori I. Mabuchi H.: Cardiac aldosterone production in genetically hypertensive rats. Hypertension, 2000;36: 495-500

55. Christ M. Wehling M.: Rapid actions of aldosterone: lymphocytes, vascular smooth muscle and endothelial cells. Steroids, 1999:64: 35-41

56. Wildling L. Hinterdorfer P. Kusche-Vihrog K. Treffner Y. Oberleithner H.: Aldosterone receptor sites on plasma membrane of human vascular endothelium detected by a mechanical nanosensor. Pflugers Arch. 2009;458: 223-230

57. Christ M. Douwes K. Eisen C. Bechtner G. Theisen K. Wehling M.: Rapid effects of aldosterone on sodium transport in vascular smooth muscle cells. Hypertension, 1995;25: 117-123

58. Leite-Dellova D.C. Oliveira-Souza M. Malnic G. Mello-Aires M.: Genomic and nongenomic dose-dependent 
biphasic effect of aldosterone on $\mathrm{Na}+/ \mathrm{H}+$ exchanger in proximal S3 segment: role of cytosolic calcium. Am. J. Physiol. Renal Physiol. 2008;295: F1342-F1352

59. Rossol-Haseroth K, Zhou Q, Braun S, Boldyreff B, Falkenstein $E$, Wehling $M$, Lösel RM. Mineralocorticoid receptor antagonists do not block rapid ERK activation by aldosterone, Biochem Biophys Res Commun. 2004 May 21;318(1):281-8.

60. Gromotowicz A, Osmólska U, Mantur M, Szoka P, Zakrzeska A, Szemraj J, Chabielska E. Prothrombotic aldosterone action--a new side of the hormone], Postepy Hig Med Dosw (Online). 2010 Oct 18;64:471-81.

61. Marzolla V, Armani A, Feraco A, De Martino MU, Fabbri A, Rosano G, Caprio M. Mineralocorticoid receptor in adipocytes and macrophages: a promising target to fight metabolic syndrome, Steroids. 2014 Dec;91:46-53.

62. Luther JM. Aldosterone in vascular and metabolic dysfunction, Curr Opin Nephrol Hypertens. 2015 Nov 14.

63. Zennaro MC, Caprio M, Fève B. Mineralocorticoid receptors in the metabolic syndrome, Trends Endocrinol Metab. 2009 Nov;20(9):444-51.

64. Funder JW, Primary Aldosteronism: New Answers, New Questions, Horm Metab Res. 2015 Nov 20.

65. Pelliccia F, Rosano G, Patti G, Volterrani M, Greco C, Gaudio C. Efficacy and safety of mineralocorticoid receptors in mild to moderate arterial hypertension, Int J Cardiol. 2015 Dec 1;200:8-11.

66. Parthasarathy HK, Ménard J, White WB, Young WF Jr, Williams GH, Williams B, Ruilope LM, McInnes GT, Connell JM, MacDonald TM, A double-blind, randomized study comparing the antihypertensive effect of eplerenone and spironolactone in patients with hypertension and evidence of primary aldosteronism, J Hypertens. 2011 May;29(5):980-90.

67. Karagiannis A, Tziomalos K, Papageorgiou A, Kakafika Al, Pagourelias ED, Anagnostis P, Athyros VG, Mikhailidis $D P$, Spironolactone versus eplerenone for the treatment of idiopathic hyperaldosteronism, Expert Opin Pharmacother. 2008 Mar;9(4):509-15.

68. Späth M, Korovkin S, Antke C, Anlauf M, Willenberg HS, Aldosterone- and cortisol-co-secreting adrenal tumors: the lost subtype of primary aldosteronism, Eur J Endocrinol. 2011 Apr;164(4):447-55.

69. Willenberg HS, Späth M, Maser-Gluth C, Engers R, Anlauf M, Dekomien G, Schott M, Schinner S, Cupisti K, Scherbaum WA. Sporadic solitary aldosterone- and cortisol-co-secreting adenomas: endocrine, histological and genetic findings in a subtype of primary aldosteronism, Hypertens Res. 2010 May;33(5):467-72.

70. Fujimoto K, Honjo S, Tatsuoka H, Hamamoto Y, Kawasaki $Y$, Matsuoka A, Ikeda H, Wada Y, Sasano H, Koshiyama $\mathrm{H}$, Primary aldosteronism associated with subclinical Cushing syndrome, J Endocrinol Invest. 2013 Sep;36(8):564-7.

71. Hiraishi K, Yoshimoto T, Tsuchiya K, Minami I, Doi M, Izumiyama H, Sasano H, Hirata Y.Clinicopathological features of primary aldosteronism associated with subclinical Cushing's syndrome, Endocr J. 2011;58(7):543-51.

72. Omura M, Saito J, Matsuzawa Y, Nishikawa T. Supper-selective ACTH-stimulated adrenal vein sampling is neces- sary for detecting precisely functional state of various lesions in unilateral and bilateral adrenal disorders, inducing primary aldosteronism with subclinical Cushing's syndrome, Endocr J. 2011;58(10):919-20.

73. Markou A, Sertedaki A, Kaltsas G, Androulakis II, Marakaki C, Pappa T, Gouli A, Papanastasiou L, Fountoulakis S, Zacharoulis A, Karavidas A, Ragkou D, Charmandari E, Chrousos GP, Piaditis GP. Stress-induced Aldosterone Hyper-Secretion in a Substantial Subset of Patients With Essential Hypertension, J Clin Endocrinol Metab. 2015 Aug;100(8):2857-64.

74. Yen RF, Wu VC, Liu KL, Cheng MF, Wu YW, Chueh SC, Lin WC, Wu KD, Tzen KY, Lu CC; TAIPAI Study Group, 1311-6beta-iodomethyl-19-norcholesterol SPECT/CT for primary aldosteronism patients with inconclusive adrenal venous sampling and CT results, Nucl Med. 2009 Oct;50(10):1631-7.

75. Spyridonidis TJ, Apostolopoulos DJ. Is there a role for Nuclear Medicine in diagnosis and management of patients with primary aldosteronism? Hell J Nucl Med. 2013 May-Aug;16(2):134-9.

76. Lombardi CP, Raffaelli M, De Crea C, Rufini V, Treglia G, Bellantone R. Noninvasive adrenal imaging in hyperaldosteronism: is it accurate for correctly identifying patients who should be selected for surgery? Langenbecks Arch Surg. 2007;392:623-628

77. Nomura K, Kusakabe K, Maki M, Ito Y, Aiba M, Demura $\mathrm{H}$. lodomethylnorcholesterol uptake in an aldosteronoma shown by dexamethasone-suppression scintigraphy: relationship to adenoma size and functional activity, J Clin Endocrinol Metab. 1990 Oct;71(4):825-30.

78. Goh BK, Tan YH, Chang KT, Eng PH, Yip SK, Cheng CW. Primary hyperaldosteronism secondary to unilateral adrenal hyperplasia: an unusual cause of surgically correctable hypertension. A review of 30 cases. World J Surg. 2007 Jan;31(1):72-9.

79. Tomaschitz A, Ritz E, Pieske B, Aldosterone and parathyroid hormone: a precarious couple for cardiovascular disease, Cardiovasc Res. 2012 Apr 1;94(1):10-9.

80. Tomaschitz A, Pilz S. Interplay between sodium and calcium regulatory hormones: a clinically relevant research field, Hypertension. 2014 Feb;63(2):212-4.

81. Zhang LX, Gu WJ, Li YJ et al. PTH Is a Promising Auxiliary Index for the Clinical Diagnosis of Aldosterone-Producing Adenoma. Am J Hypertens. 2015 Aug 24.

Acceptance for editing: 2016-06-29 Acceptance for publication: 2016-06-30

Correspondence address: Department of Endocrinology, Metabolism and Internal Medicine University of Medical Sciences 49 Przybyszewskiego St, 60-355 Poznan, Poland 